\title{
All in with Google Slides: Virtual engagement and formative assessment in introductory sign language linguistics
}

\author{
Leah C. Geer*
}

\begin{abstract}
My goals as an instructor are to be transparent and approachable and to cultivate a community of learners. The transition to virtual instruction in Sign Language Structure and Usage presented significant challenges. I wondered how students could engage effectively with me, with each other, and with course content; how students could identify what they understood and on what they needed further instruction. To address these questions, I went all in with Google Slides to build engaging, searchable, self-paced slide presentations with built-in formative assessments. COVID-19 inspired this shift in slide creation, but I envision using these slides going forward because they are more equitable and more inclusive. If students are not able to come to class for any reason, they can review videos and complete selfassessments, just as they would in class. Anecdotal remarks suggest this approach appeals to a wider range of students and learning styles, but further study should explicitly examine student perceptions of this slide format. Other faculty in my college have recently expressed interest in adopting this style of presentation in their own courses.
\end{abstract}

Keywords. ASL linguistics; Google Slides; mixed-media presentations; virtual instruction; built-in formative assessment

1. Introduction. I wrote in my Teaching Philosophy for my 2019 faculty review that my goal as an instructor is, "to create a classroom which is a safe space for a community of learnersin which each individual has something valuable to contribute." This goal is grounded in three organizing principles:

- social justice and inclusion;

- participation in hands-on, engaged learning;

- reflection on and responses to student needs and feedback.

But in my introductory linguistics course - Sign Language Structure \& Usage - I had been struggling to meet students where they were. Many felt like they had nothing to contribute or brought no experiences/knowledge of value to the class. I examined this in a presentation for a Professional Learning Committee I was a part of during the 2019-2020 academic year (Geer, 2020b). Then the COVID-19 pandemic struck and I realized this goal, and these organizing principles, could not have been more relevant.

Prior to COVID, I had recorded video lectures, especially for fall classes when I often miss classes for High Holidays, but at the time I did not consider what students needed from these presentations to make them truly accessible and to align with my main goal. These lectures were presented using the same slides I would have used to teach in person, and I said what I would have said if I were explaining the content of the slide live and in class.

\footnotetext{
* I am grateful to Michal Temkin Martinez, Kazuko Hiramatsu, and other members of the LSA Faculty Learning Community on Scholarly Teaching in Linguistics for hosting the Opportunity for Scholarly Teaching, Education and Research panel and facilitating these proceedings. I also appreciate helpful comments from an anonymous reviewer in improving manuscript clarity. Author: Leah C. Geer, California State University, Sacramento (leah.geer@csus.edu).
}

(C) 2021 Author(s). Published by the LSA with permission of the author(s) under a CC BY license. 
The problem was that there was no way to gauge how well students were understanding these videos - both from a language perspective; do they understand my ASL, as mostly second language learners - and do they understand the concepts I am teaching. There were three additional issues with these pre-COVID video lectures: 1) the slide presentations I used were large and difficult to share without saving the document with several slides to a page; this meant losing links to additional resources embedded in the slides; 2) the videos were very long, often upwards of 40-60 minutes, which is hard to sit through in the best of circumstances; and 3) the videos are not searchable. While I provided an outline of each video with time stamps, it was stillnot a terribly user-friendly approach (see Figure 1). There was a disconnect between my instructional videos and the slide file. More importantly, there was a disconnect between what I say I strive for in my classroom, how I make my materials, and how students are (in)able to interact with them.

Descripción?

This is Part 1 (of 3 ) of the video lecture on Chapter 10: Language Policy and Planning.

**Part 1 Contents**

1. Class re-cap (how this lesson fits into our course) :12

2. 10.1 Written \& Unwritten rules for language use 1:39

3. Unwritten rules 2:08

4. Written rules 3:25

5. 10.2 Language practices 5:34

6. Language practices in sign languages 6:34

7. Cultural conflict in communication 13:54

Part 2 link: https://youtu.be/drhjxuYjEyl

Part 3 link: https://youtu.be/UuK9kVlpKoA

Figure 1. Video contents with time stamps for Part 1 of a video lecture on Language Policy and Planning (https://youtu.be/dLiWddEVq0Y)

2. Transitioning to virtual instruction. In March 2020, my university announced that all classes would move to virtual format in response to the pandemic. We were given four days to plan how we would maintain continuity of instruction in our courses. Just as Greenhow, Robelia \& Hughes (2009) discussed, we were at yet another place in the "digital age" and in need of reconceptualizing our classrooms in an attempt to understand how we could continue to serve our students virtually.

In this transition, I continued to make slides and video lectures as I had done in the past. That got me (and my students) through the rest of the semester. Students seemed pleased. One reported that, "during this unprecedented time ... [the professor] has been understanding and continually trying to make it the best learning environment for us"; another said that I did, "AMAZING handling the transition \& still provided us with a great learning experience." WhileI was obviously relieved to know that students felt positively about how the course turned out, during the summer I started to reflect on what would be better than "good enough" as I looked toward Fall 2020. This reflection is an important part of one of my organizing principles for teaching. 
As I considered revising and improving my materials, I knew I wanted to become more transparent. I also reflected on issues of equity. During the sudden transition to virtual learning, many students found themselves struggling with insufficient internet to access Zoom meetings,not having a reliable webcam to make and submit ASL video essays, among other issues. This, as well as preparing for other courses, led me to start experimenting with Google Slides.

I had only ever built a few Google Slides presentations before - mostly when I did not know what device I would be presenting from and wanted to ensure integrity of formatting. As it turned out, this was exactly what I needed for my course materials - a slide format that was easy to build, easy to embed materials in, did not require uploading/downloading huge files, and would look the same regardless of the device it was being displayed on.

So I went all in with Google Slides for my linguistics course, and other courses as well.There are four key features to this approach. For numbers 1, 2, and 4, see Figure 2. For number 3, see Figure 3.

1. Videos on slides are short - no longer than three minutes.

2. A bulleted list indicating what is discussed in the slide video creates better navigability students can quickly search for, find, and re-watch the specific content they need to study.

3. Built-in formative assessments allow students to gauge their progress and mastery of course content.

4. Icons direct students to additional materials they may find helpful for deepening their understanding of specific topics. They also ensure that ASL is always represented visually with links to ASL signs/data (Börstell 2019).
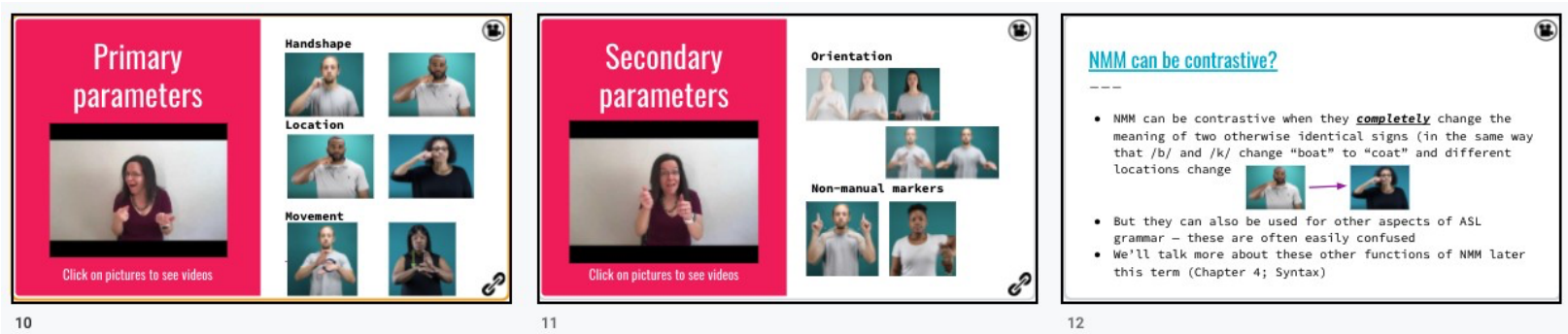

Figure 2. Three slides illustrating key features number $1,2, \& 4$. The videos for Primary Parameters and Secondary Parameters are 1:03 and 1:07, respectively. The longest video in this particular presentation is 1:54. Please note that videos are in ASL without English captions as proficiency in ASL is required for this course. If you do need to create captions in YouTube, see Geer, 2021b and for a tutorial for captioning videos in sign language see Geer, 2021a. ${ }^{1}$

\footnotetext{
${ }^{1}$ The full presentation is available here: https://docs.google.com/presentation/d/1e_qRsPYbwJeP_6313aPVxGjXek2TvL81Rs-hhiSDjA/edit?usp=sharing.
} 

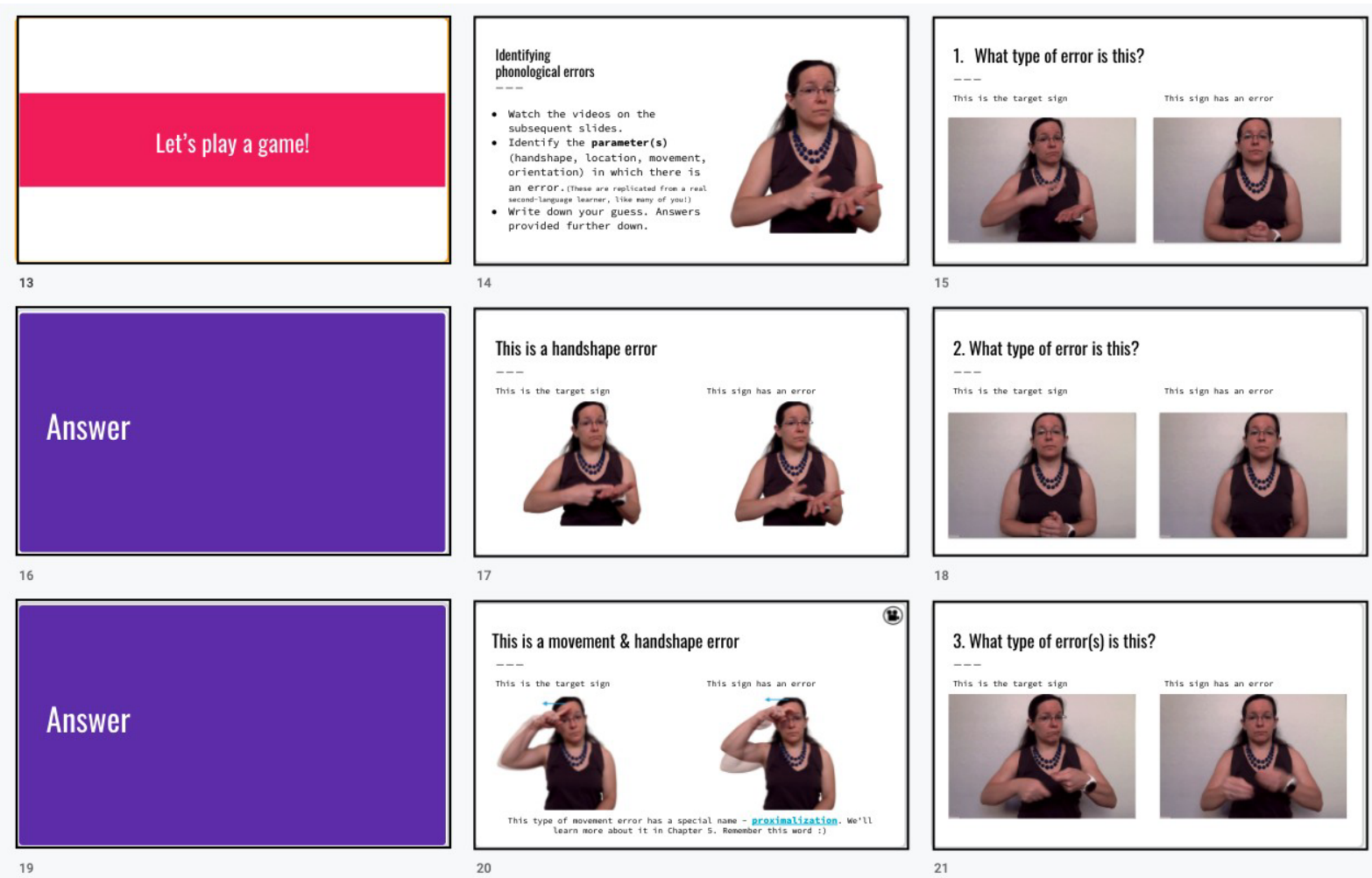

Figure 3. A series of nine slides illustrating built-in formative assessment. The task is explained (slide 14), and a slide separates the question (slides $15,18,21$ ) from the answer (slides 17,20) sostudents have time to consider the answer and can control when they advance to the answer slide.

3. Effectiveness of Google Slides. The transition to Google Slides has been well received. In Fall 2020, one student said that, "During this pandemic crisis, [the professor] has been nothingbut helpful and supportive," while another shared, "This class was the most highly engaging and fun class I have taken this semester." While these comments do not specifically mention the slide presentations, they show that students felt supported and found the course engaging and enjoyable.

In Spring 2021, I administered an anonymous Google Forms survey at week 6 to gauge how the course was going. No one commented specifically on the slide presentations, but one student noted that I, "explain everything very well...[a]s well as add notes to further understandthe activity or lecture." It is unclear whether this is referring to our synchronous sessions on Zoom or the explanations provided in Google Slides.

4. JEDI teaching and learning from student voices. As I noted in my PLC presentation (Geer 2020b), "students don't know what they know" when it comes to linguistics. This is whereI feel it most important to discuss justice, equity, diversity, and inclusion (JEDI).

There are several issues my students have faced in the past year which my Google Slides (attempt to) address. These include having:

- access to strong enough wifi to access Zoom class sessions;

- the ability to attend class sessions;

- the ability to self-motivate without the structure of a formal classroom (Geer 2020a);

- the ability to engage with the content as one would in a face-to-face class. 
Before COVID-19, students relied on campus resources like computer labs and WiFi. The unavailability of those resources disproportionately impacted students from marginalized backgrounds. With those resources no longer available, some students were unable to Zoom at all, while others had intermittent, low quality access. Meanwhile, other students lost work because of the pandemic and/or switched jobs. Sometimes that meant having a scheduling conflict with class sessions. Finally, in my old video lectures, I presented as I would live in class,skipping over interactive portions of the presentation.

The way I design and deploy my Google Slides addresses most of these issues.

- Google Slides presentations load even with poor internet connection. Once loaded, students can save the presentation to their own Google Drive, then elect to view the presentation offline (Docs Editors Help 2021). This means that when students lack sufficient internet and potentially cannot access Zoom classes, they can still access the main content of the lecture via Google Slides. This also helps to address the tech issues students reported in Geer (2020a).

- Likewise, if students are not able to attend class because of work conflicts, or for any other reason, they can still access the main content of the lecture at a time that is more convenient.

- Because the slides have built-in engagement in the form of formative assessments, students are not just passively reading the slides and watching embedded videos; they have a task to complete and at the end of the task, students see an answer key. In the case that students were unable to come up with the correct answer, they then know to contact me for further assistance in mastering that concept.

- An additional issue this presentation style addresses is different learning styles. I will return to this in the subsequent "Beyond COVID-19" section.

Taken together, more of the lecture content is available to students within the slide presentation itself, regardless of whether they're able to attend class and what kind of internet/devices are available to them.

5. Beyond COVID-19. Going forward, I will continue to build slides in this way (for all my classes, not just linguistics) because it suits a wider range of students and learning styles. Google Slides are easily shared with the click of a link. They do not require storing or downloading huge files, and they can be saved to one's own drive and set to be viewed offline. It is also easier to embed helpful resources directly into the slides for students to explore. Students who like to review slides before class can do so with this approach, watching the embedded videos in the slides which elaborate on concepts introduced on the slide. In addition, this approach is more equitable and inclusive. If students are not able to come to class for any reason, they can review videos and complete self-assessments, then ask questions as necessary, just as they would in class.

This approach is also significantly more sustainable than my previous video lectures. The old procedure required first making the slides (which took 1-2 hours), then recording/editing videos, which could take 5-8 hours. If I needed to introduce new information or change how I explained something based on student feedback, I had to edit the slides then completely refilm/reedit the whole video. Conversely, producing a Google Slide deck does the work of the previous slide presentation and video all in one. Presentations take 1-2 hours to build; recording/editing the short videos takes around an hour. For revisions, I only need to refilm the affected video(s), which are at most, 3-4 minutes in length. These slides are effective for distance learning and more accessible 
even when we return to face-to-face instruction, and they will be easier to maintain and keep updated as time goes on.

6. Conclusion. The impetus of my transition to using Google Slides (and other programs in the Google Suite) was the COVID-19 pandemic but that transition has completely changed how Ithink about building materials and challenged how I imagine students will engage with these materials. Moreover, this transition has also encouraged me to think about how to make materials which are more just, more equitable, speak to a more diverse set of students, and are more inclusive of different learning styles. As I move forward as a teacher-scholar, I will bring these notions with me into every class I approach and in all of the instructional materials I create for those classes.

\section{References}

Börstell. C. 2019. "Always present sign languagedata in a visual format (videos/images) without relying solely on glossing.” Is this a good definition? [Twitter post: @c_borstell]. https://twitter.com/hashtag/GlossGesang?src=hashtag_click.

Docs Editors Help. 2021. Work on Google Docs, Sheets, \& Slides offline. [Web page]. https://support.google.com/docs/answer/6388102?co=GENIE.Platform\%3DDesktop\&hl=en.

Geer, Leah. C. 2020a. Student voices: Learning through COVID-19. [Vlog: May 25]. https://www.leahgeer.com/vlogblog/summer2020\#h.p_NYHi1kZhqkmg.

Geer, Leah. C. 2020b, December 11. Students don't know what they know about linguistics.[Poster presentation]. Center for Teaching and Learning Professional Learning Culminating Event. California State University, Sacramento.

Geer, Leah. C. (2021a). Making ASL subtitles with ELAN \& uploading to YouTube. [Unpublished tutorial]. https://docs.google.com/document/d/10xmYd48dVWniFmxrnbbVHLohID3oLdonJ6yChwUw UPs/edit?usp=sharing.

Geer, Leah. C. (2021b). Revising English subtitles on YouTube. [Unpublished tutorial]. https://docs.google.com/document/d/16QU8SpkF5jR8HXvA6I5mBxE_xHaXFhkhn_1ZrN7rWw/edit?usp=sharing.

Greenhow, Christine, Beth Robelia \& Joan E Hughes. 2009. Learning, teaching, and scholarship in a digital age: Web 2.0 and classroom research: What path should we take now? Educational Researcher 38(4). 246-259 https://doi.org/10.3102/0013189X09336671. 